\title{
A step forward to a more efficient wastewater treatment by membrane surface modification via polymerizable bicontinuous microemulsion
}

\author{
Francesco Galiano $^{\mathrm{a}}$, Alberto Figoli ${ }^{\mathrm{a}, *}$, Shamim Ahmed Deowan ${ }^{\mathrm{b}}$, Daniel Johnson ${ }^{\mathrm{c}}$, Sacide \\ Alsoy Altinkaya ${ }^{\mathrm{d}}$, Lucia Veltri ${ }^{\mathrm{e}}$, Giorgio De Luca ${ }^{\mathrm{a}}$, Raffaella Mancuso ${ }^{\mathrm{e}}$, Nidal Hilal ${ }^{\mathrm{c}, \mathrm{f}}$, \\ Bartolo Gabriele ${ }^{\mathrm{e}}$, Jan Hoinkis ${ }^{\mathrm{b}}$ \\ a National Research Council of Italy (CNR), Institute on Membrane Technology (ITM), Via P. Bucci cubo 17/C, 87036 Arcavacata di Rende (CS), Italy \\ ${ }^{\mathrm{b}}$ Institute of Applied Research (IAF), Karlsruhe University of Applied Sciences, Moltkestr. 30, 76133 Karlsruhe, Germany \\ ' Centre for Water Advanced Technologies and Environmental Research (CWATER), Swansea University, Singleton Park, Swansea SA2 8PP, UK \\ d Department of Chemical Engineering, Izmir Institute of Technology, Gulbahce Kampusu, 35430 Urla, Izmir, Turkey \\ e Department of Chemistry and Chemical Technologies, University of Calabria, Via P. Bucci cubo 12/C, 87036 Arcavacata di Rende (CS), Italy \\ ${ }^{\mathrm{f}}$ Qatar Environment and Energy Research Institute, Doha, Qatar
}

\section{A R T I C L E I N F O}

\section{Article history:}

Received 26 November 2014

Received in revised form

10 February 2015

Accepted 14 February 2015

Available online 4 March 2015

\section{Keywords:}

Polymerizable surfactants

Polymerizable bicontinuous

microemulsions

Surface modification

Water treatment

Membranes

\begin{abstract}
A B S T R A C T
An innovative hydrophilic and anti-fouling coating material for application in membrane technology for wastewater treatment has been developed by polymerization of a polymerizable bicontinuous microemulsion (PBM) and used for surface modification of a commercial flat polyethersulfone (PES) membrane. The novel nanostructured coating has been produced using acryloyloxyundecyltriethylammonium bromide (AUTEAB) as a co-polymerizable surfactant, obtained through a synthetic method characterized by a lower cost and a higher reproducibility compared to other known polymerizable surfactants. The novel composite membranes have been characterized and compared with the uncoated PES membranes. Coated membranes resulted in a smoother surface and a higher hydrophilicity with respect to the uncoated ones, and showed a particular nano-size channel-like morphology making them highly resistant to the fouling phenomenon. The covalent anchorage of the surfactant on the membrane surface ensured the embedment of the molecule in the polymeric matrix avoiding its leaching and also leading the coated membranes to have significant antimicrobial activity, which is very important for reducing the biofouling phenomenon.

All these aspects make the tailored coating material an ideal and efficient coating for modifications of commercial membrane surfaces, to be used in membrane processes in wastewater treatment.
\end{abstract}

(c) 2015 Elsevier B.V. All rights reserved.

\section{Introduction}

Water is essential for the life of all living organisms and its preservation and responsible use is one of the global challenges that humanity will face in the next future. The United Nations estimated that by 2025 two-thirds of humanity will have to cope with the problem of water scarcity turning this precious resource into the blue gold of the third millennium.

The question of water scarcity is directly linked to the evidence that the world's water resources are not unlimited and the increasing demand of water due to urbanization and population growth together with global climate changes have a very strong effect on water availability [1].

\footnotetext{
* Corresponding author. Tel.:+390984492027.

E-mail address: a.figoli@itm.cnr.it (A. Figoli)
}

The increasing worldwide demand for clean water is pushing more and more the market to find new strategies and innovative alternatives that can be applied for water reuse. The development of efficient wastewater treatment technologies can, thus, give complete answers to many of the problems related to water purification. In particular, membrane processes devoted to wastewater treatment are gaining more and more attention thanks to their high efficiency, energy saving systems, easy scale-up and flexibility.

In this study, a novel surface modification method based on polymerizable bicontinuous microemulsions (PBMs) was developed and proposed for a potential application in wastewater treatment.

A particularly interesting feature of microemulsions lies in the possibility to polymerize these bi-phasic systems by employing, between the components of the microemulsion, suitable monomers, usually dispersed in the oil channels. The surfactant used to stabilize the microemulsion may be either non-polymerizable or 
polymerizable; clearly, in the latter case, the polymerizable surfactant also acts as a co-monomer in the polymerization process. The thus obtained microemulsions are called polymerizable bicontinuous microemulsions (PBMs). Their polymerization produces transparent porous polymeric micro- and nanostructured solid materials [2-4], which have gained increasing attention during the last years due to their possible application in catalysis, as drug delivery systems and, last but not least, as coating materials in separation processes through membrane functionalization [5]. In fact, the polymerization of the monomers present in the oil channels leads to the formation of a solid polymer matrix, which can be used as coating for surface modification of known and, possibly, even of commercial membranes, with the aim of improving their performances without the need for developing new performing materials. PBMs have been widely investigated and employed, for instance, as coating material for hollow fiber membranes [6]. On the other hand, Gan et al. studied the polymerization of methyl methacrylate (MMA) using different types of polymerizable and non-polymerizable surfactants [2,3,7,8]. In 1996 Chieng et al. [9], produced porous polymeric membranes using the anionic surfactant sodium dodecyl sulfate (SDS) and the cationic surfactant dodecyltrimethylammonium bromide (DTAB). In an another approach, a double-chained surfactant, didodecyldimethylammonium bromide (DDAB) was used for the polymerization of MMA and silica gels $[10,11]$. In these works, the optimal polymerization conditions (i.e. temperature and microemulsion composition) have been identified and discussed for tailoring the pore size of the PBM membrane produced. However, the above-mentioned PBMs have not been ever applied for the surface modification of flat sheet membranes, and not designed for a possible application in the field of wastewater treatment.

Surface modification techniques are, in particular, aimed at reducing membrane fouling (caused by the accumulation of organic substances on membrane surface) or biofouling (caused by accumulation of biomolecules or even microorganisms on membrane surface) by acting on parameters strongly related to this phenomena, such as membrane roughness, hydrophilicity, and membrane charge $[12,13]$.

Fouling and biofouling are, in fact, major drawbacks in membrane operations, which cause a rapid decline in membrane performances and in membrane durability [14-16]. Many strategies have been applied so far in order to control the fouling, such as: reducing the flux, increasing the aeration rate, back-flushing the membrane, using physical or chemical cleanings [17]. However, the possibility to reduce fouling and/or biofouling by preparing membranes with intrinsic anti-fouling properties via surface membrane modification, remains the most attractive, but still challenging, approach. Improvements of the antifouling properties were obtained by Shao et al. [18] by the surface modification of polyvinylidene fluoride (PVDF) membranes by means of the self-polymerization of polydopamine acting as "bio-glue" for the entrapment of hydrophilic $\mathrm{TiO}_{2}$ nanoparticles. The hydrophilicity and the water flux of the modified membranes were increased. The anti-fouling properties of modified membranes were proved by using bovine serum albumin (BSA) protein and attributed to the increased hydrophilicity of the membrane surface. A flux recovery of more than $90 \%$ after BSA filtration was obtained.

Cheng et al. [19] worked on the surface modification of PES membranes by interfacial polymerization of amino-functional polyethylene glycol (PEG) and trimesoyl chloride. The higher hydrophilic moiety, the positive surface charge and larger pore size were the main responsible of the improved performances in terms of salt rejection and water permeability. Furthermore, the properties exhibited by the modified membranes, may also contribute to an important anti-fouling activity.
In the present work, a novel PBM has been prepared, polymerized, and used as a coating material for surface modification of commercially available PES membranes. The coating obtained here, in particular, has been realized by employing the polymerizable surfactant acryloyloxyundecyltriethylammonium bromide (AUTEAB), obtained by a simple and particularly efficient synthetic strategy. AUTEAB has been used as an expedient alternative to the similar surfactant acryloyloxyundecyltrimethylammonium bromide (AUTMAB), which has already been used in the literature for other applications $[2,4,20]$. As a matter of fact, the synthesis of AUTEAB, reported in the present work, allows for a much higher yield and reproducibility (and therefore to significantly lower production costs making it possible to scale-up) when compared to those already known such as AUTMAB or other polymerizable surfactants. In addition, the novel formulation of the PBM developed in this work, which employs AUTEAB in conjunction with the other components of the microemulsion, has led to a coating with significant anti-fouling and antibiofouling properties, connected with its hydrophilic character and to the antimicrobial activity of the covalently bonded cationic surfactant [21]. These properties have been verified by the considerably improved performances of commercial PES membranes after their surface modification with this newly developed nanostructured interconnected channels coating.

Improved hydrophilicity, smoother surface, channel-like structure and antimicrobial activity are the main benefits exhibited by PBM membranes making them ideal candidates to be applied in wastewater treatment processes, such as membrane bioreactors (MBRs), where membranes with anti-fouling and anti-biofouling properties are highly desired.

\section{Experimental}

\subsection{General}

The organic compounds synthesized in this work were fully characterized by ${ }^{1} \mathrm{H}$ NMR, ${ }^{13} \mathrm{C}$ NMR and FT-IR spectroscopies. IR data were taken with Perkin Elmer Paragon 1000 PC FT-IR spectrometer. NMR spectra were performed at room temperature in $d_{6^{-}}$ DMSO solutions with TMS as the internal standard, using a Bruker DPX Avance 500 spectrometer. Chemical shifts $(\delta)$ and coupling constants $(J)$ are given in ppm and $\mathrm{MHz}$, respectively.

\subsection{Synthesis of the surfactant acryloyloxyundecyltriethylammonium bromide (AUTEAB)}

The synthesis of a pure polymerizable surfactant is a key step in the formation of microporous materials from PBMs. All the chemicals used for the AUTEAB synthesis were purchased from Sigma-Aldrich with purity higher than $98 \%$ (analytical grade) and were used as such without further purification. AUTEAB has been synthesized in 59\% overall yield starting from commercially available 11-bromoundecanol by a two-step procedure involving esterification of 11-bromoundecanol with acryloyl chloride to give 11-bromoundecyl acrylate followed by the reaction of the latter with $\mathrm{Et}_{3} \mathrm{~N}$ (Scheme 1), as detailed below.

\subsubsection{1st step: esterification of 11-bromoundecanol with acryloyl chloride to give 11-bromoundecyl acrylate}

To a stirred solution of 11-bromoundecanol (5.0 g, $20 \mathrm{mmol})$ in anhydrous $\mathrm{MeCN}(110 \mathrm{~mL})$, maintained at room temperature in a Schlenk flask, was added 2,6-di-tert-butyl-4-methylphenol (30 mg, $0.14 \mathrm{mmol}$; used as radical inhibitor), followed by acryloyl chloride (dropwise; $2.26 \mathrm{~g}, 25 \mathrm{mmol}$ ), and activated molecular sieves $3 \AA$ ( $4.3 \mathrm{~g})$. The flask was sealed, and the mixture allowed to stir at $90{ }^{\circ} \mathrm{C}$ for $24 \mathrm{~h}$. After cooling, the mixture was filtered in 


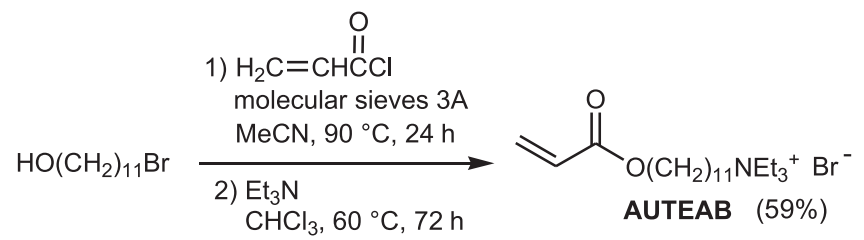

Scheme 1. Synthesis of the polymerizable surfactant acryloyloxyundecyltriethylammonium bromide (AUTEAB).

order to remove the molecular sieves, the solvent removed under vacuum and the residue purified by column chromatography on silica gel using 9:1 hexane:ethyl acetate as eluent, to give pure 11bromoundecyl acrylate as a colorless oil (yield: $88 \%, 5.35 \mathrm{~g}$ based on starting 11-bromoundecanol). IR (film): $\nu / \mathrm{cm}^{-1}=2927(\mathrm{~m})$, $2855(\mathrm{~m}), 1725$ (s), $1466(\mathrm{~m}), 1273(\mathrm{~m}), 1192(\mathrm{~s}), 1060$ (m), $984(\mathrm{~m})$, $810(\mathrm{w}) .{ }^{1} \mathrm{H}$ NMR $\left(300 \mathrm{MHz}, d_{6}\right.$-DMSO): $\delta=6.36$ (dd, $J=17.4,1.6$, $1 \mathrm{H}, \mathrm{CHH}=\mathrm{CH}), 6.11(\mathrm{dd}, J=17.3,10.4,1 \mathrm{H}, \mathrm{CHH}=\mathrm{CH}), 5.78(\mathrm{dd}$, $J=10.4,1.6,1 \mathrm{H}, \mathrm{CH}=\mathrm{CH}), 4.12\left(\mathrm{t}, J=6.7,2 \mathrm{H}, \mathrm{OCH}_{2}\right), 3.38(\mathrm{q}$, $\left.J=7.2,2 \mathrm{H}, \mathrm{CH}_{2} \mathrm{Br}\right), 1.89-1.75\left(\mathrm{~m}, 2 \mathrm{H}, \mathrm{CH}_{2} \mathrm{CH}_{2} \mathrm{Br}\right), 1.72-1.59(\mathrm{~m}, 2 \mathrm{H}$, $\left.\mathrm{OCH}_{2} \mathrm{CH}_{2}\right), 1.48-1.23\left[\mathrm{~m}, 14 \mathrm{H}, \mathrm{OCH}_{2} \mathrm{CH}_{2}\left(\mathrm{CH}_{2}\right)_{7}\right] .{ }^{13} \mathrm{C} \mathrm{NMR}(126 \mathrm{MHz}$, $d_{6}$-DMSO): $\delta=165.6,129.4,129.1,64.4,33.2,33.0,29.45,29.43$, $29.3,28.9,28.8,28.3,26.0$.

\subsubsection{Step: quaternization of 11-bromoundecyl acrylate with} triethylamine to give acryloyloxyundecyltrimethylammonium bromide (AUTEAB)

The method of Zhang et al. [22] was employed, with some modifications. To a solution of 11-bromoundecyl acrylate $(5.35 \mathrm{~g}$, $17.5 \mathrm{mmol})$ in anhydrous $\mathrm{CHCl}_{3}(8 \mathrm{~mL})$, maintained under nitrogen at room temperature in a Schlenk flask, was added triethylamine $(1.96 \mathrm{~g}, 19.4 \mathrm{mmol})$ dropwise. The flask was sealed, and the mixture allowed to stir at $60{ }^{\circ} \mathrm{C}$ for $24 \mathrm{~h}$. After cooling, diethyl ether $(80 \mathrm{~mL})$ was added dropwise to the filtrate maintained under stirring. The resulting white precipitate was filtered and washed with diethyl ether, to give pure acryloyloxyundecyltrimethylammonium bromide (AUTEAB) as a colorless solid, mp $43-44{ }^{\circ} \mathrm{C}$ (yield:67\%, $4.74 \mathrm{~g}$ based on starting 11-bromoundecyl acrylate). IR (KBr): $\nu / \mathrm{cm}^{-1}=2928(\mathrm{~m})$, 2852 (m), 1719 (s), 1636 (m), 1456 (w), 1384 (m), 1295 (w), 1202 (m), 1056 (w). ${ }^{1} \mathrm{H}$ NMR (500 MHz, $d_{6}$-DMSO): $\delta=6.29$ (dd, $J=17.6,1.4,1 \mathrm{H}$, $\mathrm{CH}=\mathrm{H}=\mathrm{CH}), 6.15(\mathrm{dd}, J=17.6,10.2,1 \mathrm{H}, \mathrm{CHH}=\mathrm{CH}), 5.92(\mathrm{dd}, J=10.2$, $1.4,1 \mathrm{H}, \mathrm{CHH}=\mathrm{CH}), 4.08\left(\mathrm{t}, J=6.5,2 \mathrm{H}, \mathrm{OCH}_{2}\right), 3.23(\mathrm{q}, J=7.2,6 \mathrm{H}$, $\left.3 \mathrm{NCH}_{2} \mathrm{CH}_{3}\right), 3.08-3.13\left(\mathrm{~m}, 2 \mathrm{H}, \mathrm{CH}_{2} \mathrm{CH}_{2} \mathrm{~N}\right), 1.52-1.62(\mathrm{~m}, 4 \mathrm{H}$, $\left.\mathrm{CH}_{2} \mathrm{CH}_{2} \mathrm{CH}_{2} \mathrm{~N}\right), 1.21-1.34\left[\mathrm{~m}, 14 \mathrm{H}, \mathrm{OCH}_{2}\left(\mathrm{CH}_{2}\right)_{7}\right], 1.15(\mathrm{t}, J=7.2,9 \mathrm{H}$, $\left.3 \mathrm{NCH}_{2} \mathrm{CH}_{3}\right) .{ }^{13} \mathrm{C}$ NMR (126 MHz, $d_{6}$-DMSO): $\delta=165.4,131.3,128.3$, 64.0, 55.9, 51.9, 28.8, 28.73, 28.69, 28.5, 28.4, 28.0, 25.7, 25.2, 20.8, 7.1.

\subsection{Construction of phase diagram}

In order to identify the microemulsion concentration range, a pseudoternary phase diagram was constructed using the titration method. Two different cases were evaluated, with and without the cosurfactant HEMA. In the first case, the single phase region was determined by titrating dropwise with water, at room temperature $\left(25^{\circ} \mathrm{C}\right)$, specific amounts of MMA and AUTEAB at the weight ratio of $1: 9,2: 8,3: 7,4: 6,5: 5,6: 4,7: 3,8: 2$ and $9: 1$.

The samples were classified microemulsions when they appeared visually clear. In the second case, the single phase region was determined by mixing MMA and 2-hydroxylethyl methacrylate (HEMA) at a weight ratio of 7:3. AUTEAB was then added to MMA/HEMA mixtures at the weight ratio of $1: 9,2: 8,3: 7,4: 6,5: 5$, $6: 4,7: 3,8: 2$ and $9: 1$. All the samples were finally titrated dropwise with water, at room temperature $\left(25^{\circ} \mathrm{C}\right)$, and they were classified as microemulsions when they appeared clear and not turbid. For both cases, the same procedure was repeated 3 times and the average of these results was taken for the construction of the phase diagram.

\subsection{Microemulsion conductivity}

Conductivity measurements were carried out by Eutech Instruments PC 2700. Microemulsions were prepared at different water content. The initiators were not added to the microemulsion. The measurements were taken at room temperature (about $22^{\circ} \mathrm{C}$ ) and each measurement was repeated three times and the average of the results obtained was considered.

\subsection{Microemulsion composition and polymerization}

All the chemicals used for preparing microemulsions were purchased from Sigma-Aldrich with purity higher than 98\% (analytical grade).

The composition of the microemulsion was:

1) Methyl methacrylate (MMA), used as monomer constituting the oil phase of the microemulsion.

2) Water, used as the aqueous phase of the microemulsion.

3) Lab-made polymerizable surfactant AUTEAB, used to lower the surface tension of the microemulsion facilitating the formation of a single phase;

4) 2-Hydroxylethyl methacrylate (HEMA), used to enhance the dispersion of the oil and water phase.

5) Ethylene glycol dimethacrylate (EGDMA), added as cross-linker in order to consolidate the final membrane structure.

6) Ammonium persulfate (APS) and $N, N, N^{\prime}, N^{\prime}$-tetramethyl ethylenediamine (TMEDA), added as redox initiators in order to promote the polymerization.

The preparation of the microemulsion was carried out as follows: the monomer MMA (21 wt\%) and water ( $41 \mathrm{wt} \%$ ) were first added to a flask in the required amount. The surfactant AUTEAB ( $25 \mathrm{wt} \%$ ) was then added and the immediate and spontaneous formation of a transparent and homogenous dispersion was observed. The cosurfactant HEMA (10 wt\%) and the cross-linker EGDMA (3 wt\%) were also added.

The solution was then kept at the desired temperature (between $20^{\circ} \mathrm{C}$ and $25^{\circ} \mathrm{C}$ ) and finally $20 \mathrm{mM}$ of redox initiators (APS and TMEDA) were added to the microemulsion, which was purged with nitrogen gas for at least $1 \mathrm{~min}$.

When the microemulsion, reached the suitable viscosity, it was cast on a commercial ultrafiltration PES membrane (UP150 T supplied by Microdyn Nadir) surface in a chamber under nitrogen atmosphere and controlled temperature (between $20^{\circ} \mathrm{C}$ and $25^{\circ} \mathrm{C}$ ). The suitable viscosity of the microemulsion was determined by visual judgment. However, at the set working temperature $\left(20-25^{\circ} \mathrm{C}\right)$ the optimal microemulsion viscosity was reached in 5 min after the addition of redox initiators (including the $1 \mathrm{~min}$ of nitrogen purge). These conditions (temperature and time) have been used in all experiments.

In details, the PES membrane was firstly attached to a glass plate and it was accommodated into the nitrogen chamber where the nitrogen was let to flush in. A heater, located inside the chamber, provided to carefully control the set temperature. Then, after the above-mentioned time of $5 \mathrm{~min}$, the microemulsion was cast on the PES membrane using a casting knife of $250 \mu \mathrm{m}$. The PBM coating was left to polymerize overnight and it was completely transparent (see Fig. 1).

The commercial PES membrane was supplied by the company filled with glycerol in order to preserve the pore structure. The PES membrane was used for PBM coating as it was without any pretreatment in order to limit the penetration of the coating into 
a

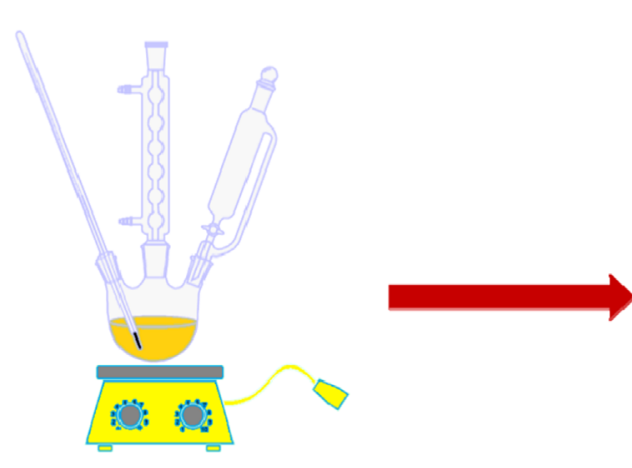

Synthesis of the surfactant $\mathrm{b}$

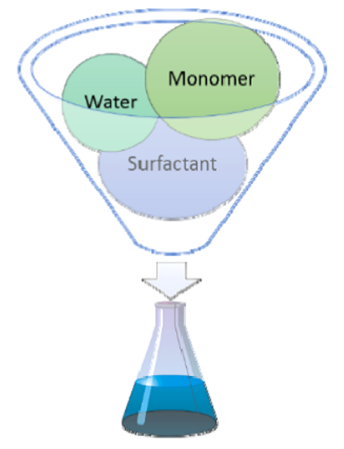

Microemulsion preparation

d
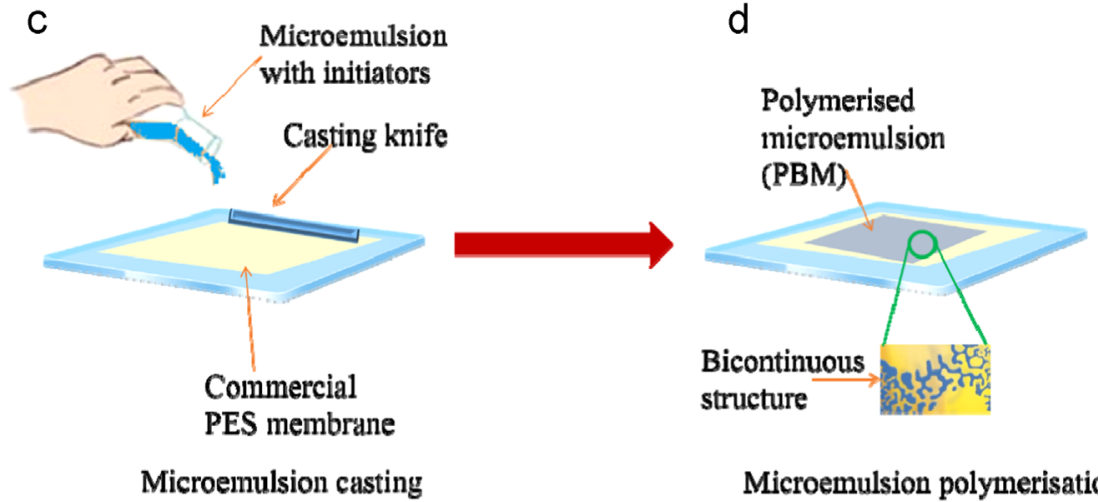

Microemulsion polymerisation

Fig. 1. Schematic illustration of the different steps carried out in PBM membrane preparation.

the membrane pores (filled with glycerol). However, when the PES membrane was applied in the characterization tests, the following pretreatment protocol was used in order to remove the glycerol and release the pores: (i) $1 \mathrm{~h}$ washing in $25 \mathrm{wt} \%$ isopropanol solution; (ii) $1 \mathrm{~h}$ washing in distilled water; (iii) further washing in distilled water overnight.

PBM coated membranes were subjected to the same pretreatment protocol before their use. Once used, both membranes (PBM and PES) were kept in glycerol solution (30 wt\% in water) in order to prevent the collapse of the pores.

\subsection{Weight loss determination}

Weight loss determination tests were carried out on the pure polymerized PBM material (not coated on PES membrane) in order to determine the amount of unreacted material by different extraction processes. For calculating the weight loss of membranes, the polymerized membrane was first weighed and then dried overnight in the oven at $50{ }^{\circ} \mathrm{C}$ in order to remove the water. The membrane was then soaked for $2 \mathrm{~h}$ in toluene in order to extract the unpolymerized MMA and finally the membrane was treated with water at $50{ }^{\circ} \mathrm{C}$ for $3 \mathrm{~h}$ in order to remove the unreacted surfactant. The amount of water and unreacted material was determined by measuring the weight loss after each extraction. The loss was calculated by using the following equation (Eq. (1)):

$W_{\mathrm{l}}=\frac{W_{\mathrm{i}}-W_{\mathrm{f}}}{W_{\mathrm{i}}} \times 100$ where $W_{1}$ is the weight loss, $W_{\mathrm{i}}$ is the initial weight of the membrane before each drying or extraction and $W_{\mathrm{f}}$ is the final weight of the membrane after each drying or extraction.

\subsection{Infrared spectroscopy (FT-IR)}

The presence of PBM coating on PES membrane surface was determined by FT-IR ATR Spectrometer (Perkin Elmer, Spectrum One).

\subsection{Scanning electron microscopy (SEM)}

The SEM instrument, used for the morphology investigation of coated and PES membranes, was a Hitachi Field Emission SEM (model S-4800). The surface and cross-section of membranes were evaluated. Cross sections were made through the membranes by first immersing the membrane in liquid nitrogen before cutting from the reverse side using a fresh razor blade. All samples were sputter coated with an approximately $15 \mathrm{~nm}$ thick layer of gold prior to imaging.

\subsection{Atomic Force Microscopy (AFM) and surface roughness}

AFM measurements were performed on a Multimode AFM with Nanoscope IIIa controller (Veeco, USA) using manufacturersupplied software. All measurements were carried out under ambient laboratory conditions using tapping mode. TESP (nominal spring constant $20-80 \mathrm{~N} / \mathrm{m}$ ) cantilevers (Bruker AXS) were used throughout. All images used had a resolution of $512 \times 512$ pixels. All roughness values quoted are root mean squared (RMS) roughness values calculated by the instrument software from the 


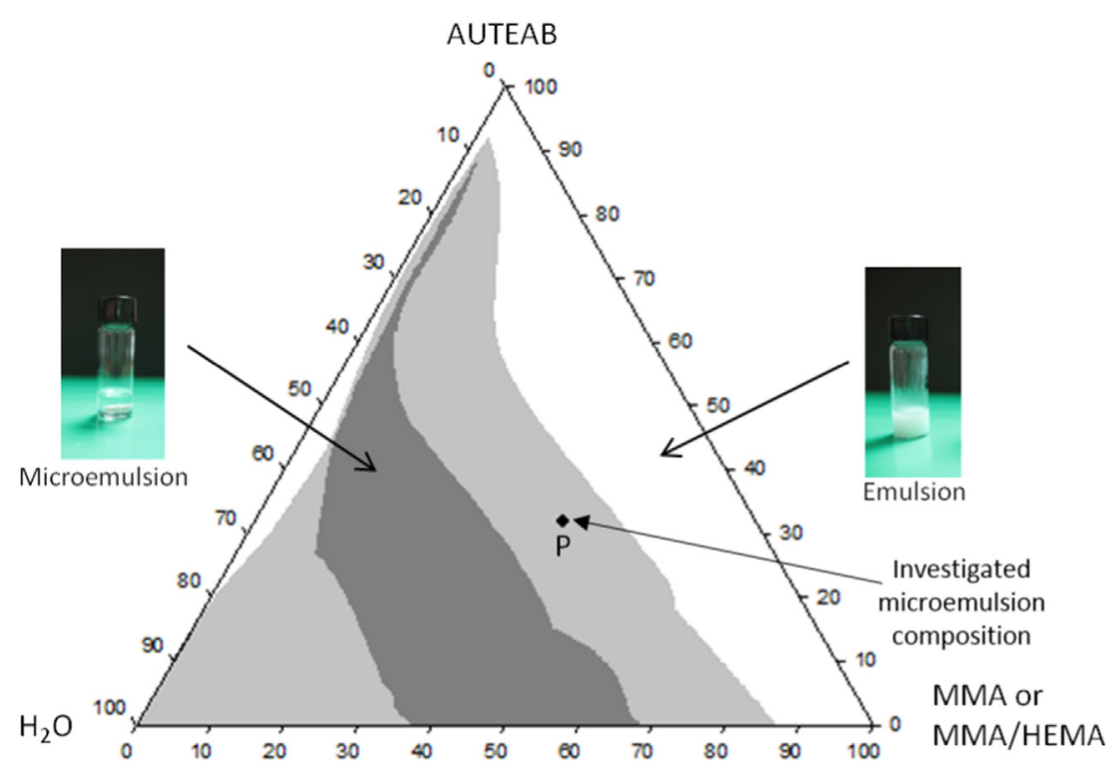

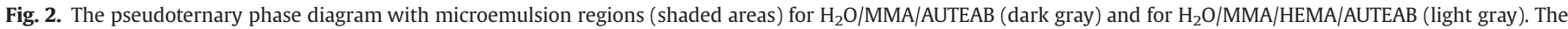
point $\mathrm{P}$ represents the investigated concentration system.

following equation (Eq. (2)):

$\mathrm{RMS}=\sqrt{\frac{\sum\left(Z_{\mathrm{i}}\right)^{2}}{n}}$

where $Z_{\mathrm{i}}$ is the current height deviation from the mean plane of the image and $n$ is the number of data points in the image. All images were flattened to remove sample tilt prior to calculation of RMS values. As many roughness parameters, including RMS values, scale with the image size [23], all images used in this work were at the same image size of $1 \times 1 \mu \mathrm{m}^{2}$ to ensure comparisons of surface roughness between membrane samples were comparing like with like.

\subsection{Contact angle measurements (CAM)}

Contact angle measurements were performed using ultrapure water by the method of the sessile drop using a CAM200 instrument (KSV Instrument LTD, Finland). The resolution of the instrument was $800 \times 600$ pixel. For each sample, at least 10 measurements were taken; the average value and the corresponding standard deviation were then calculated. Water CAM were performed for the active side of PES membranes and for the coating side of coated membranes.

\subsection{Antimicrobial activity}

The following protocol was used for the determination of the surfactants' antimicrobial activity. Antibacterial tests were started by preparing growth media using Mueller-Hinton broth and agar. Prepared agar, which was sterilized at $121^{\circ} \mathrm{C}$, was cooled to appropriate temperature, then poured to the petri dishes in $15 \mathrm{~mL}$ amounts and left for drying overnight. On the next day, petri dishes were checked for contamination. Then Escherichia coli bacteria was applied onto four of them by using a needle holder and $E$. coli bacterial cultures were grown on nutrient agar plates at $37{ }^{\circ} \mathrm{C}$ overnight. Then, a sufficient amount of $E$. coli colonies were dissolved in $0.9 \% \mathrm{NaCl}$-water to adjust the turbidity to Mcfarland no. 0.5 which corresponds to $10^{8}$ Colony-Forming Unit (CFU)/ml. Sterile tissue culture plates (6 well with $10 \mathrm{~mL}$ volumes) were obtained from Becton Dickinson Labware Company. $0.1 \mathrm{~mL}$ of bacteria suspension and $1.9 \mathrm{~mL}$ of Mueller-Hinton broth were

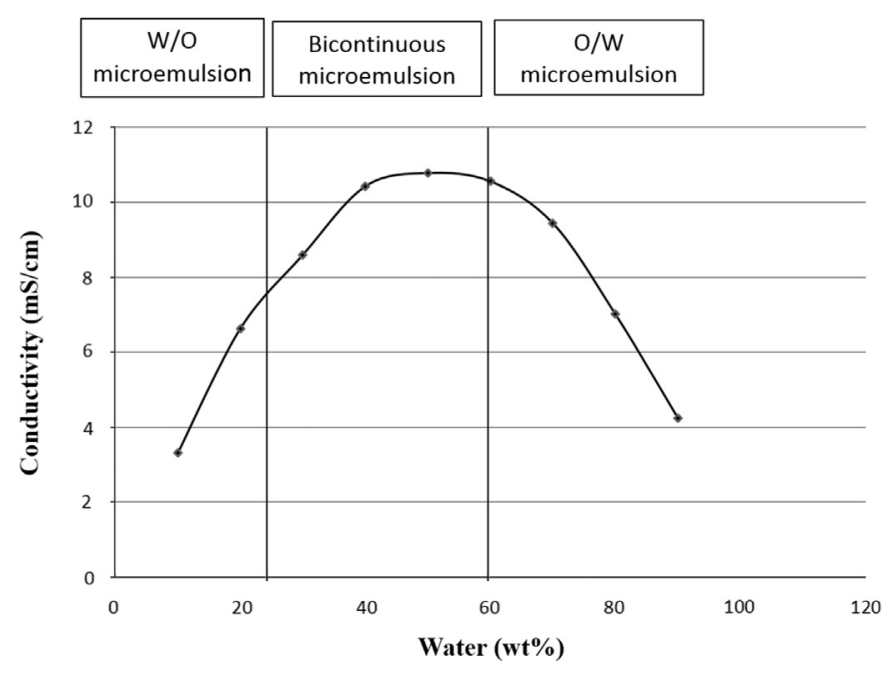

Fig. 3. AUTEAB conductivity measurements at different aqueous solutions.

Table 1

Weight loss determination of the PBM coated membranes prepared in this work.

\begin{tabular}{lll}
\hline $\begin{array}{l}\text { Drying-loss of } \\
\text { water (wt\%) }\end{array}$ & $\begin{array}{l}\text { Toluene extraction-loss of } \\
\text { MMA (wt\%) }\end{array}$ & $\begin{array}{l}\text { Hot } \mathrm{H}_{2} \mathrm{O} \text { extraction-loss of } \\
\text { surfactant (wt\%) }\end{array}$ \\
\hline $22 \pm 2$ & $0 \pm 2$ & $5 \pm 2$ \\
\hline
\end{tabular}

added into the well containing different amounts of antibacterial material (surfactant) and they were incubated for $24 \mathrm{~h}$. After that, $0.1 \mathrm{~mL}$ of liquid sample was added on nutrient agar plates and spread over the plates. Plates were incubated at $37^{\circ} \mathrm{C}$ for $24 \mathrm{~h}$. Finally, grown cells were counted on the plates.

For evaluating the antibacterial properties of PES and PBM nanostructured coated membranes, E. coli solution was serially diluted using Mueller-Hinton broth to $100 \mathrm{CFU} / \mathrm{ml}$ from the $10^{6}$ $\mathrm{CFU} / \mathrm{ml}$ stock. $0.6 \mathrm{~mL}$ of the diluted solution which corresponds to $60 \mathrm{CFU}$, was spread onto the $0.05 \times 0.05 \mathrm{~m}^{2}$ membranes. In order to allow complete absorption of bacteria solution on membrane surface at room temperature, they were pre-incubated for $2 \mathrm{~h}$, 
followed by $24 \mathrm{~h}$ incubation at $37^{\circ} \mathrm{C}$ on Mueller-Hinton agar plates. At the end of the incubation, number of bacteria present on the membrane surface was counted. All the materials were sterilized at standard conditions, i.e. $120^{\circ} \mathrm{C}, 15 \mathrm{psi}$ and for $30 \mathrm{~min}$ before use.

\subsection{Water permeability and fouling tests}

Water permeability was measured at room temperature $\left(22^{\circ} \mathrm{C}\right)$ by using a laboratory ultrafiltration cross-flow testing cell at the pressure of 1 bar. Water was pumped, by means of a peristaltic pump, through the membrane on an area of $0.00116 \mathrm{~m}^{2}$.

Water permeability $\left(P_{\mathrm{w}}\right)$ was calculated by collecting the permeate for a fixed duration and then by applying the following

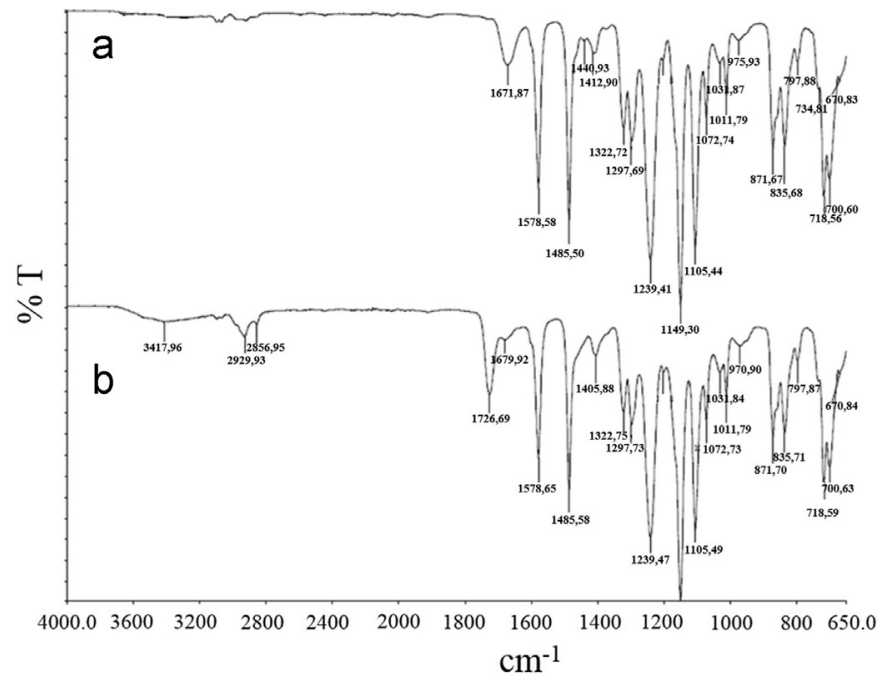

Fig. 4. FT-IR spectra of PES (a) and PBM membrane (b). equation (Eq. (3)):

$P_{\mathrm{w}}: \frac{Q}{\operatorname{Atp}}$

where $Q$ is the volume of permeate expressed in liters, $A$ is the area of membrane expressed in $\mathrm{m}^{2}, t$ is the time expressed in hours and $p$ is the pressure expressed in bar.

Fouling tests were carried out by using humic acid (HA) (purchased from Alfa Aesar GmbH \& Co KG, Germany) as model foulant with a concentration of $100 \mathrm{mg} / \mathrm{L}$. Filtration tests were carried for $24 \mathrm{~h}$ both for PES and PBM membranes by using an auto-controlled ultrafiltration (UF) cross-flow testing cell manufactured by company SIMAtec GmbH, Germany and the HA permeability $\left(P_{\mathrm{HA}}\right)$ was recorded. The dimensions of the active membrane area used were $0.214 \mathrm{~m} \times 0.04 \mathrm{~m}$ covering $0.00856 \mathrm{~m}^{2}$. The feed solution from the feed tank was pumped at room temperature into the membrane module and through the membrane at desired pressure. The permeate and concentrate coming out of the membrane module were recirculated back to the feed tank. After treatment with HA, the membranes were flushed with water at 0.5 bar for $3 \mathrm{~h}$ and the new water permeability $\left(P_{\mathrm{R}}\right)$ was measured before removing the membranes from the testing cell. The reduction and recovery in water permeability and the appearance of the membrane after back-flushing gave an indication of the membrane's fouling propensity. Furthermore, the fouling layer thickness was measured by SEM analyses. The recovery and regain in water permeability were calculated as follows:

$$
\begin{aligned}
& \text { Reduction }(\%)=\left(1-\frac{P_{\mathrm{HA}}}{P_{w}} \times 100\right) \\
& \text { Recovery }(\%)=\left(\left(\frac{P_{R}-P_{\mathrm{HA}}}{P_{\mathrm{HA}}}\right) \times 100\right)
\end{aligned}
$$
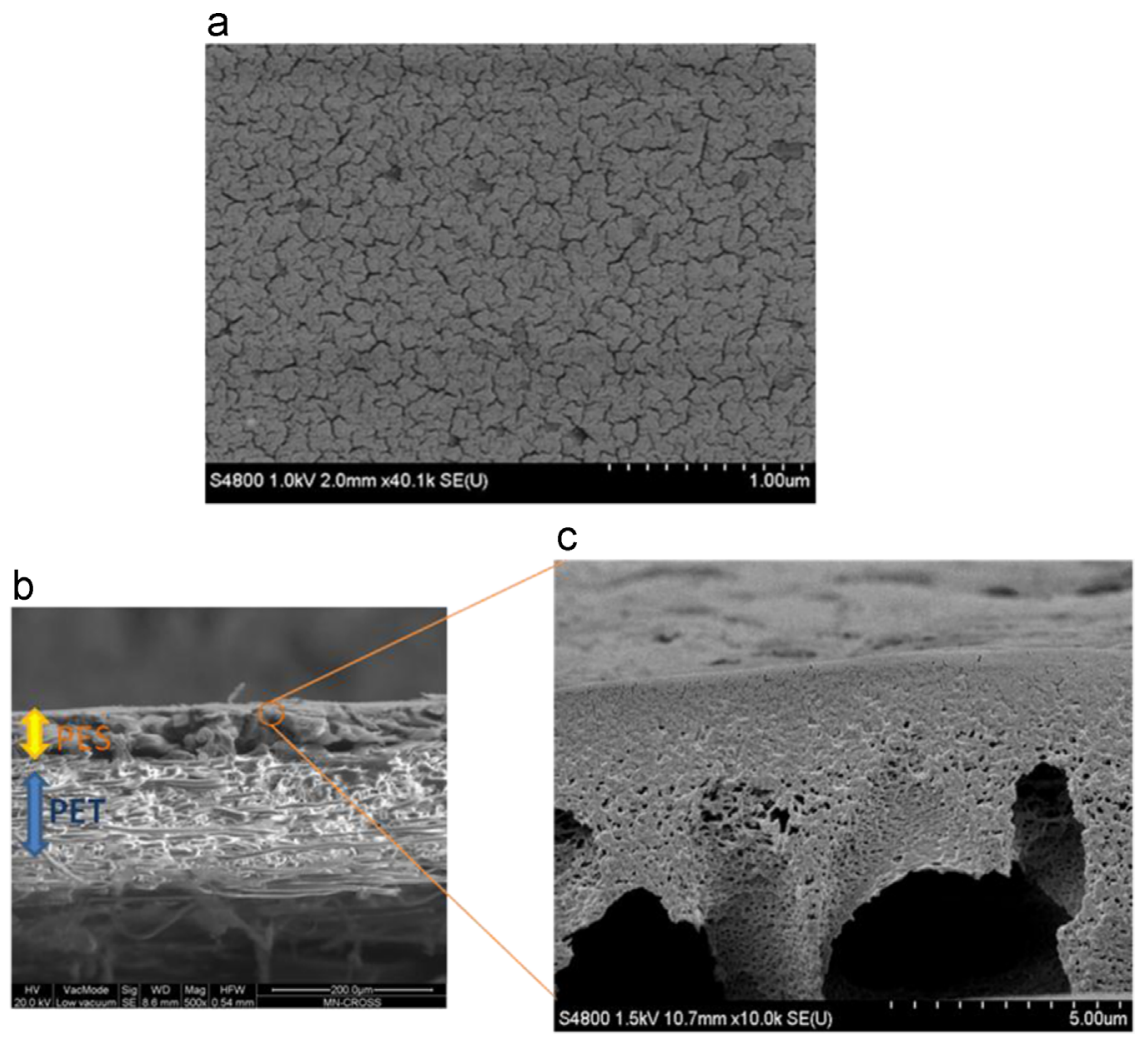

Fig. 5. SEM surface (a) and cross-section (b, c) of PES commercial membrane. 

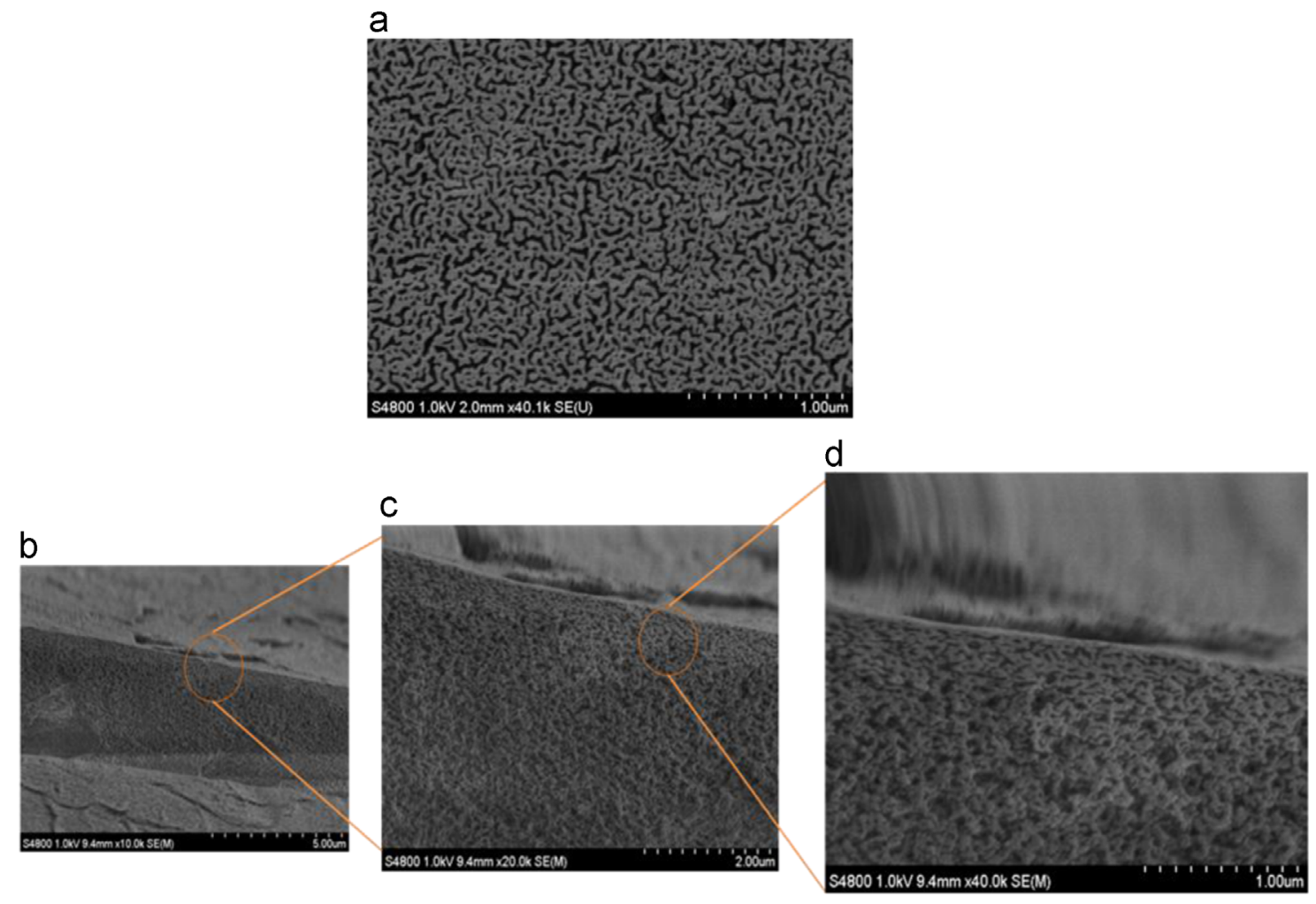

Fig. 6. SEM surface image (a) and cross-section (b-d) of PBM membrane with magnification (magnification from $\times 10,000$ to $\times 40,000$ ).

a

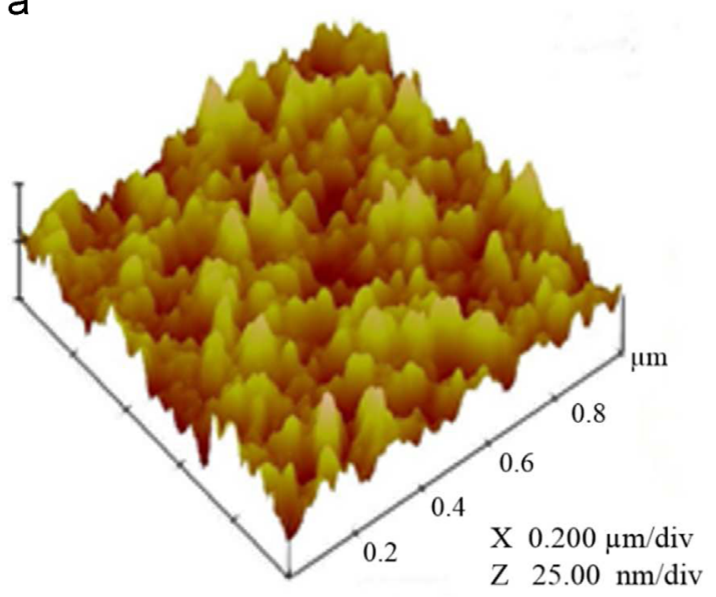

b

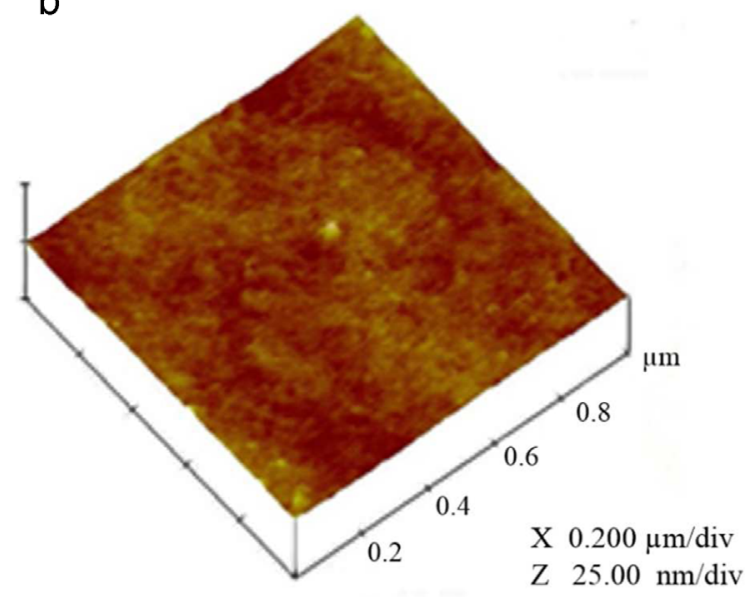

Fig. 7. AFM surface of PES (a) and PBM membrane (b).

\section{Results and discussion}

\subsection{AUTEAB synthesis}

AUTEAB was used as the polymerizable surfactant, and the synthetic route used in this work allowed reducing its production costs with respect to the analogous AUTMAB usually applied in the literature. Furthermore, the possibility of using liquid triethylamine instead of gaseous methylamine made the synthesis route more efficient and manageable, and the synthesis method more reproducible. The presence of the acrylate group makes the AUTEAB surfactant reactive and polymerizable avoiding any possibility of leaching. After the polymerization, the surfactant becomes, in fact, chemically bonded to the membrane matrix enhancing the hydrophilicity of the overall membrane [24] and guaranteeing antimicrobial activity. This also ensures preventing the leaching of the surfactant from the membrane. When polymerizable surfactants are used to prepare the microemulsion, all the components are polymerizable (except water) giving a final strong and resistant network.

\subsection{Microemulsion phase diagram}

Fig. 2 shows the pseudoternary phase diagram. The large shaded region represents the composition that can be used to prepare transparent microemulsions. In particular, the dark gray area refers to the first case evaluated where the ternary system of $\mathrm{H}_{2} \mathrm{O} / \mathrm{MMA} / \mathrm{AUTEAB}$ was used. The light gray area, on the contrary, 
borders the microemulsion range when HEMA was also considered in the microemulsion preparation. It can be noticed that, in this latter case, the area of microemulsion region is considerably wider. The enlarging single phase region can be attributed to the increased flexibility of the interfacial film due to the addition of the cosurfactant. HEMA, in fact, shifts the alignment of micellar aggregates from the liquid crystalline region to the microemulsion region [8]. Based on these results and on conductivity data the optimal bicontinuous microemulsion composition was found. The point $\mathrm{P}$ represents the investigated concentration system used to prepare the coated nano-structured membranes.

The white area in the phase diagram indicates two separate isotropic regions with the formation of turbid emulsions.

\subsection{Conductivity measurements}

Bicontinuous microemulsion composition was prepared in accordance to the specific necessity of operating in the microemulsion bicontinuous range which was determined by conductivity measurements. The bicontinuous range in the microemulsion was found between 30 and $60 \mathrm{wt} \%$ water content (see Fig. 3).

Conductivity measurements allowed to differentiate the O/W droplets, the bicontinuous microemulsion and the $\mathrm{W} / \mathrm{O}$ systems. It is known that systems with a low conductivity are associated with W/O microemulsions while systems with high conductivity are associated with $\mathrm{O} / \mathrm{W}$ microemulsions [8]. The transition from a $\mathrm{W} /$ $\mathrm{O}$ to a bicontinuous microemulsion is shown by a sharp increase in the conductivity value [3]. This variation of electrical conductivity of microemulsions as a function of water content is well established [25-27].

\subsection{Weight loss determination}

The amount of unreacted material after microemulsion polymerization was determined by measuring the weight loss of membrane after different extractions to which membranes were exposed as reported in Table 1.

The water loss was about $22 \mathrm{wt} \%$ and it was determined by drying the membrane in the oven. The weight loss after toluene extraction was null, indicating that the whole MMA was fully copolymerized within the membrane. After hot water extraction, the loss of surfactant was very low (5 wt\%) and it was due to the extraction of unreacted AUTEAB. This can be explained considering that AUTEAB is a polymerizable surfactant and, after copolymerization within the membrane matrix, it cannot be removed. This aspect is of crucial importance since the chemically linked AUTEAB remains in the PBM membrane, even during the filtration tests, accomplishing its function as an antimicrobial agent and improving the hydrophilic moiety of the membrane.

The covalent anchorage of the surfactant on the membrane surface may also allow, by anionic exchange, the entrapment of active anionic nanoparticles, such as Keggin heteropolyanions (POMs) on the membrane surface. The possibility to exchange the bromide anions of the covalently linked surfactant with POMs was recently investigated by us from a theoretical point of view [28].

\subsection{FT-IR analyses}

Fig. 4 shows the IR spectra of the unmodified PES membrane (a) and the PBM-modified membrane (b). The presence of a relatively broad absorption at $1726 \mathrm{~cm}^{-1}$ in (b) clearly indicates the presence of PBM coating. Furthermore, same IR spectrum of the PBM coating has been also observed after the water permeability tests. This proves the stability of the PBM coating on PES membrane.

\subsection{Morphological analysis: SEM}

The existence of a bicontinuous nanostructure in coated membranes was revealed by SEM analyses. This was direct evidence that the microemulsion was polymerized in the bicontinuous state and it was present, as a coating, on the PES membrane surface. During the polymerization, the water channels remained

Table 2

Cell counts in $10 \mathrm{~mL}$ well plates for AUTEAB surfactant.

\begin{tabular}{ll}
\hline AUTEAB amount (gr) & Cells count \\
\hline 0.0012 & Too many \\
0.0013 & Too many \\
0.0018 & 0 \\
0.0022 & 0 \\
0.0041 & 0 \\
0.0076 & 0 \\
0.0104 & 0 \\
0.0115 & 0 \\
0.0165 & 0 \\
0.0200 & 0 \\
\hline
\end{tabular}

Table 3

RMS roughness, CAM and antimicrobial activity of PES and PBM-coated membrane.

\begin{tabular}{lcll}
\hline Membrane & RMS roughness $(\mathrm{nm})$ & CAM (deg) & Antimicrobial ctivity \\
\hline PES & $6.59 \pm 0.32$ & $68 \pm 3$ & No \\
PBM & $0.387 \pm 0.13$ & $47 \pm 3$ & Yes \\
\hline
\end{tabular}

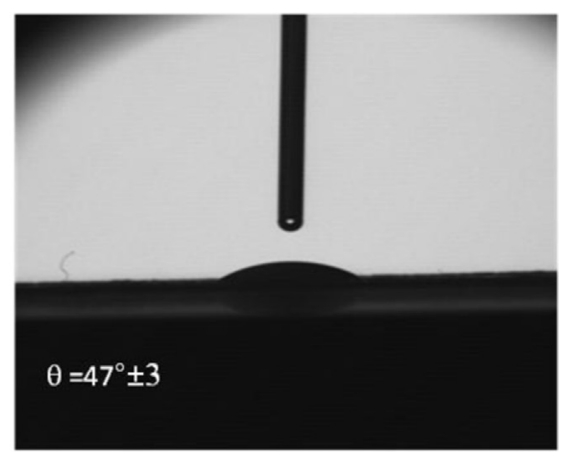

PBM membrane

Fig. 8. Water droplet on PES commercial and PBM coated membrane surface. 
unchanged, while the oil channels polymerized forming the polymer matrix of the membrane, giving, as the final result, an interconnected network of oil and water channels. This particular configuration, where elongated or "slotted" pores are present, is related to the important anti-fouling properties exhibited by PBM membranes. Pore geometry has a big influence on the fouling phenomenon which is responsible to cake layer formation at membrane surface and therefore on the decline of filtrate flow. Bromley et al. [29] studied the effect of pore geometry on fouling formation by comparing both membranes with circular and slotted pores. From the results obtained by filtration tests containing particles of a specific diameter, it was found that the critical flux for slotted pores membrane was much higher than the one observed with circular pore membrane. In the latter case, in fact, the particles deposit at the pore entrance, thus hindering the fluid flow to pass through. In the case of slotted pore membrane, on the contrary, the fluid can flow through the open regions of the pore not blocked by the particle deposition. The experiments showed that slotted pores are able to limit the particle bridging over the pores responsible for cake deposition and fouling formation. This observation could also be assumed for the channel like (bicontinuous) structure presents in the coated membranes prepared in the present work and showed in Fig. 6a. The water unpolymerized channels are comparable to slotted pores and they can ideally work in the same way. The proved anti-fouling properties of PBM membranes can, thus, be also justified by their morphological structure.

In Fig. 5a, the surface of commercial PES membrane, used as support for PBM coating, is shown. The membrane surface appears porous.

The commercial membrane was a composite membrane made of two layers: a top porous active PES layer and an underlying support of polyethylene terephtalate (PET) responsible for the mechanical strength of the membrane. This structure was clearly visible in Fig. 5b where a cross-section and a magnification (c) of the PES commercial membrane are depicted.

As can be seen in Fig. 6a, the surface of the coated membranes presented the typical bicontinuous structure made up of an interconnected network of polymer channels (white strips) and water channels (dark strips). The dimensions of the water channels (representing the porous part of the membrane and estimated by SEM pictures) were in the range of $30-50 \mathrm{~nm}$ in width. These structures were randomly distributed across the overall membrane surface.

From cross-section images (Fig. 6b-d) the PBM coating on PES membrane was clearly visible. The measured thickness of the

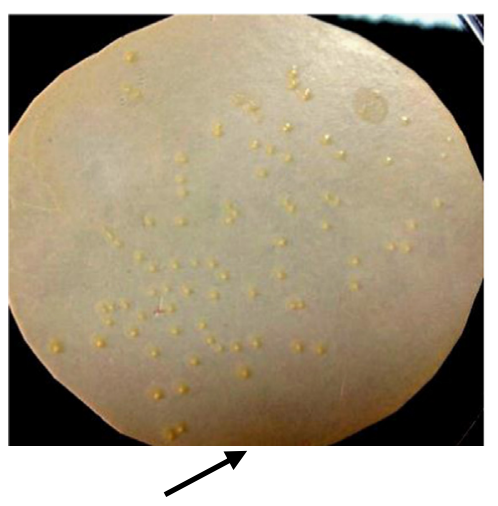

Commercial PES membrane: No antibacterial activity was found coating was less than $1 \mu \mathrm{m}$. The PBM coating ranged from a minimum of 0.2 to a maximum of $3 \mu \mathrm{m}$.

\subsection{Surface analysis: AFM}

Fig. 7 shows typical $1 \times 1 \mu \mathrm{m}^{2}$ AFM scans of the undmodified PES membrane (a) and of the coated membrane (b) respectively (both images have the same vertical scale with $25 \mathrm{~nm}$ per division). As can be seen, there is a considerable difference in the height of surface features. This is reflected in the RMS roughness values calculated for each membrane of $6.59 \mathrm{~nm}( \pm 0.32)$ and $0.387 \mathrm{~nm}$ ( \pm 0.13 ) for the PES and coated membranes respectively, with each value being an average from three scans from different parts of the membrane sample surface. This shows an approxiamately 17 fold decrease in surface roughness for the PBMmodified membrane compared with the commercial PES membrane.

The interplay between surface roughness and adhesion of foulants to membrane surfaces is complex and can be difficult to quantify. For instance, measurements between polymer latex particles and stainless steel surfaces found that generally as surface roughness decreased adhesion forces increased, with the notable exception of the least rough surface. For soft solids interacting with surfaces it has been found that the work of adhesion increases with increasing surface roughness [30]. With

\section{Table 4}

Permeation and anti-fouling properties of PES and PBM-coated membrane.

\begin{tabular}{llllll}
\hline Membrane & $\begin{array}{l}P_{\mathrm{w}}[\mathrm{L} / \\
\left.\mathrm{m}^{2} \mathrm{~h} \text { bar }\right]\end{array}$ & $\begin{array}{l}P_{\mathrm{HA}}[\mathrm{L} / \\
\left.\mathrm{m}^{2} \mathrm{~h} \text { bar }\right]\end{array}$ & $\begin{array}{l}P_{\mathrm{R}}[\mathrm{L} / \\
\left.\mathrm{m}^{2} \mathrm{~h} \text { bar }\right]\end{array}$ & $\begin{array}{l}\text { Reduction } \\
{[\%]}\end{array}$ & $\begin{array}{l}\text { Recovery } \\
{[\%]}\end{array}$ \\
\hline PES & $610 \pm 60$ & $115 \pm 15$ & $125 \pm 10$ & $81 \pm 4$ & $9 \pm 8$ \\
PBM & $200 \pm 75$ & $110 \pm 17$ & $170 \pm 12$ & $45 \pm 3$ & $54 \pm 11$ \\
\hline
\end{tabular}

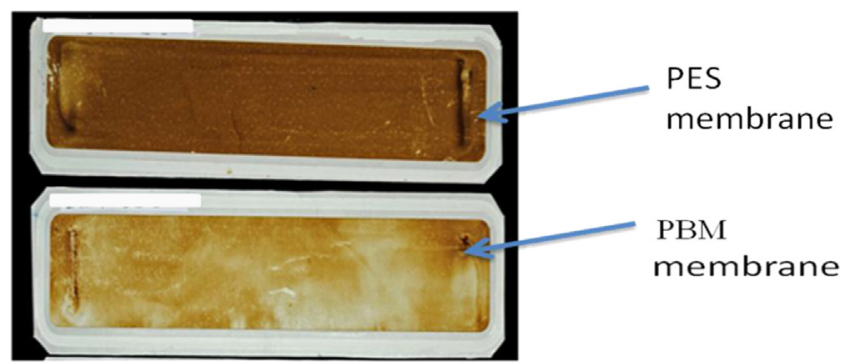

Fig. 10. Comparison of fouling effect on PES and PBM-coated membrane.

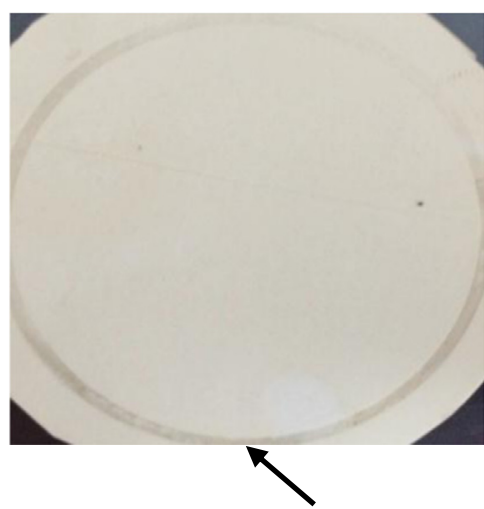

PBM coated membrane: Highly antibacterial activity was found

Fig. 9. Antimicrobial activity of PES and PBM-coated membranes. 
a
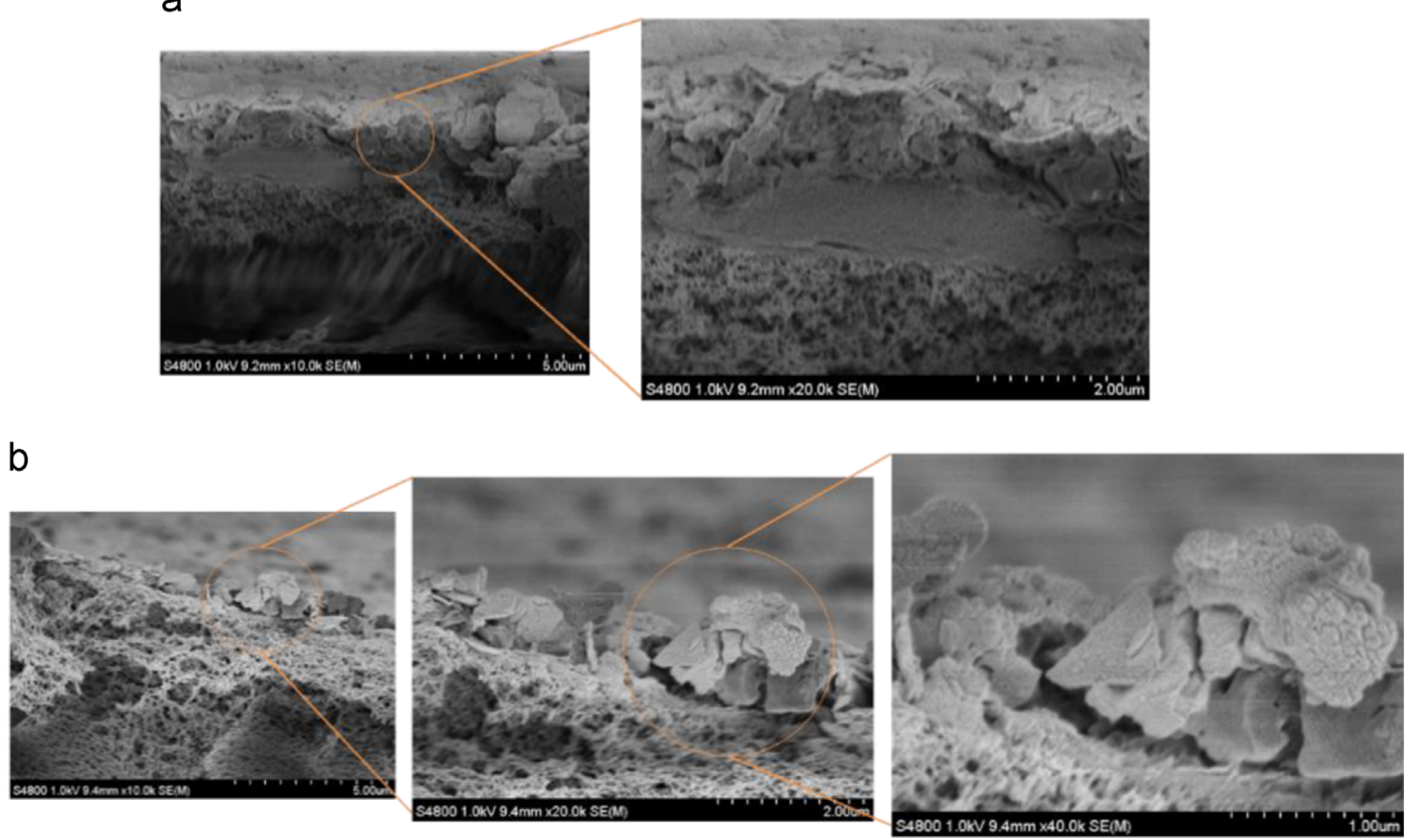

Fig. 11. HA layer on PES membrane (a) and on PBM membrane (b) with magnifications.

regards to fouling of reverse osmosis and nanofiltration membranes it has generally been observed that the greater surface area available with rougher surfaces leads to increased rates of fouling $[31,32]$. For this reason a smoother surface as exhibited by the PBM-modified membrane would be expected to show a greater resistance to fouling compared with the unmodified PES membrane.

\subsection{CAM measurements}

The relative wettability of coated and uncoated PES membranes was measured by sessile drop contact angle. Both membranes exhibited hydrophilic nature, however, this was much more pronounced in the case of membranes with a PBM layer. PES membranes presented an average contact angle of $68 \pm 3^{\circ}$ while coated membranes showed an average contact angle of $47 \pm 3^{\circ}$ (Table 3 ). Therefore, a reduction of about $30 \%$ in contact angle values was found when PBM coating was applied on PES membranes (Fig. 8).

A higher degree of hydrophilicity usually results in better performances in terms of water permeability and foulant rejection. The anti-fouling potential of hydrophilic membranes is generally due to the lower binding affinity of organic compounds to membrane surface. Organic matter, in fact, is more prone to establish hydrophobic interactions at the membrane surface causing their accumulation and a cake layer formation.

In this case, PBM-nanostructured coated membranes, due to their relative high degree of hydrophilicity, were more resistant and less prone to fouling, allowing them to operate with constant permeability for longer time (as proved by water permeability experiments).

The higher hydrophilicity of coated membranes, in comparison to uncoated PES membranes, can be explained with the following two reasons:

a) PBM-coating surface structure: as proved by roughness measurements carried out by AFM analyses, coated membranes presented a smoother surface in comparison to PES membranes. The literature data show that membrane surface morphology can affect the contact angle value. In particular, it is possible to refer to a phenomenological method proposed by Wenzel [33] relating the surface roughness to the membrane contact angle. In general

$\cos \theta^{*}=\cos \theta \times r$

where $\theta$ is Young's angle, $\theta^{*}$ is the apparent contact angle and $r$ is the surface roughness expressed here as the ratio of the actual surface area to the geometric surface area.

From the equation it can be seen that the contact angle to water of a smooth surface is, in general, lower than the one of a rough membrane. For this reason, the lower contact angle measured for coated membranes can be attributed to their smoother surface in comparison to PES membranes.

b) PBM-coating chemical composition: it is demonstrated that the presence of hydrophilic functional groups on membrane surfaces such as $-\mathrm{OH}$ and $-\mathrm{NH}_{2}$ decreases the contact angle and it is, thus, favorable for improving the hydrophilicity of the membrane. In microemulsion composition, in particular, the cosurfactant HEMA is a short-chain alcohol presenting an $\mathrm{OH}$ group. For this reason, it is possible to assume that HEMA, which was copolymerized within the microemulsion, can also enhance the affinity of the membrane surface to water molecules by exposing $-\mathrm{OH}$ groups, and thus improving the overall PBM hydrophilicity. Furthermore, even the presence of the quaternary ammonium group (positively charged), borne by polymerized AUTEAB molecules, could enhance the hydrophilicity and in its turn the anti-fouling properties of the overall PBM coating.

\subsection{Antimicrobial activity}

Quaternary ammonium salts like AUTEAB belong to a group of compounds which exhibit a strong antimicrobial activity. This activity is especially effective against gram-positive bacteria and fungi [34]. The antimicrobial activity is mainly due to the interaction of the ammonium salt with the cell membrane of microorganisms and it is more pronounced with the increase of the alkyl chain length but only up to a certain limit. If the length of the alkyl chain overcomes this limit, the antimicrobial activity decreases. 
Since the activity of quaternary ammonium salts is well known against gram-positive bacteria such as Staphylococcus aureus, the activity of AUTEAB surfactant was tested against the gram-negative bacterium E. coli.

From antimicrobial tests carried out on the surfactant, it was seen that $1.8 \mathrm{mg}$ of surfactant was enough to kill all of the E. coli (Table 2).

Antimicrobial tests were also carried out on the PBM-nanostructured coated membranes and the results were compared with the uncoated PES membranes. As shown in Fig. 9, the PBM-coated membranes showed a good antimicrobial activity. On the contrary, PES membranes did not show any antimicrobial activity.

The average number of CFUs grown on the surface of the commercial PES membrane was of about 77 , while no bacterial growth was observed on the surface of PBM coated membranes. Bacteria are considered as mainly responsible from biofouling. Their attachment to the membrane surface is followed by the adsorption of organic compounds (used as nutrients) with the following generation of polysaccharides promoting their anchorage to the membrane surface and protection from the surrounding environment. Biofouling tends to occur in many membrane processes but it is prevalent in wastewater treatment processes and in bioreactors. The anti-biofouling prerogative of coated membranes can be exploited by applying them in such processes where a direct contact of membrane surface with biologically contaminated water, is required (such as MBR).

\subsection{Water permeability and anti-fouling tests}

Anti-fouling properties of PBM-coated membranes were measured by using the model foulant humic acid (HA). Tests were carried out for $24 \mathrm{~h}$ and the water permeability of coated and uncoated PES membrane was measured before $\left(P_{\mathrm{W}}\right)$ and after treatment with $\mathrm{HA}\left(P_{\mathrm{HA}}\right)$. The data obtained with both membranes were, then, compared, and are presented in Table 4.

As it can be seen from Table 4, PES membranes showed a water permeability (WP) of $610 \mathrm{~L} / \mathrm{m}^{2} \mathrm{~h}$ bar, that was about three times higher than PBM-coated membrane (about $200 \mathrm{~L} / \mathrm{m}^{2} \mathrm{~h}$ bar). This was due to the "extra resistance" given by the PBM layer on the PES membrane. However, during treatment with HA, the permeability $\left(P_{\mathrm{HA}}\right)$ of both membranes decreased and it became almost comparable (about $110 \mathrm{~L} / \mathrm{m}^{2} \mathrm{~h}$ bar). The reduction in permeability after HA filtration was about $81 \%$ for the PES membrane, while it was about $45 \%$ for the coated membrane. This behavior can be easily explained considering the anti-fouling moiety of the PBM coating layer. Because of its smoother and more hydrophilic surface (in comparison to the PES membrane), and its particular superficial morphology, the PBM-coated membrane is more resistant to fouling. A lower reduction in permeability, when the HA was applied was, thus, observed.

Very interesting results on recovery in permeability, after cleaning of the membranes, were also observed. Both types of membranes after the treatment with HA were cleaned by pure water flushing. Ultra-pure water cross-flow washed away humic acid from the membrane surface and the new water permeability was recorded $\left(P_{\mathrm{R}}\right)$.

As reported in Table 4, the recovery in water permeability for PBM membranes was about 54\%, while PES membrane showed a water permeability recovery of just $9 \%$. This result emphasizes the lower propensity of coated membranes to be affected by fouling. Moreover, the fouling that occurred at the PBM-coated membrane surface was reversible and it could be easily removed by washing the membrane with water. The HA rejection did not change much after the PBM coating on the PES membrane. The rejection of the PBM-coated membrane was about $95 \%$ while it was about $90 \%$ for PES membrane.
In Fig. 10, two pictures of PES and PBM-coated membranes are shown after treatment with HA and subsequent cleaning with water flushing.

The surface of PES membrane appears darker and fouled in comparison to PBM-coated membrane due to the deposition of a consistent layer of HA. The coated membrane, on the contrary, looks clean and less fouled due to a lower HA accumulation on its surface. As proved by characterization tests reported above, the reasons for PBM-coated membrane anti-fouling properties are given by the sum of different factors, such as the channel-like structure, the smoother surface and higher hydrophilic nature, in comparison to the PES membrane.

An estimation of the thickness of the fouling HA layers, deposited on commercial and PBM-coated membrane surfaces, was done from the cross section SEM imaging data (Fig. 11).

By measuring the thickness of the fouling layer deposited on the surface of both membranes, the data obtained by visual inspection and water permeability tests were confirmed. PES membrane showed, in fact, a HA layer of about $1.7 \mu \mathrm{m}$, while PBM-coated membrane showed a HA layer of about $1.20 \mu \mathrm{m}$ (with a reduction of about $30 \%$ in fouling deposition).

The PBM coated membranes showed resistant lower propension to fouling toward HA than the commercial membranes, but this effect could be extended to other foulants, leading to an increase of the membrane life and decreasing the operating costs in wastewater membrane processes.

\section{Conclusions}

A novel nanostructured coating membrane material to be applied in wastewater treatment has been developed. This new material has been produced by polymerization of a bicontinuous microemulsion (PBM) involving the use of the polymerizable surfactant acryloyloxyundecyltriethylammonium bromide (AUTEAB), obtained by means of a synthetic approach characterized by a lower cost and a higher reproducibility. According to ternary phase diagram and conductivity measurements, the microemulsion bicontinuous region of the PBM developed has been identified and, from characterization tests, it was clearly proved that the bicontinuous structure was maintained even after the polymerization. Commercially available flat polyethersulfone (PES) membranes have been coated with the new material and fully characterized by SEM, AFM, CAM, antimicrobial activity, water permeability and HA tests. The novel surface-modified membranes have shown significant improved performances with respect to the commercial membrane, owing to their smoother surface (as determined by AFM analyses) remarkable hydrophilic and anti-fouling and anti-biofouling properties. The covalent anchorage of the surfactant on the membrane surface also prevented its leaching from the membrane and caused the coated membranes to possess significant antimicrobial activity, determining an appreciable reduction of the biofouling phenomenon. These properties result in a longer lifecycle of the PBM nanostructured coated membranes in comparison to uncoated ones, making them ideal candidates for applications in membrane bioreactor (MBR) technology or in other wastewater treatment processes where membranes with anti-fouling and anti-biofouling properties are highly desired. The new material developed, therefore, represents an important step forward to a more efficient treatment of wastewater, which is one of the most important issue of modern society. Furthermore, this coating opens new perspectives for new applications in several fields, spanning from sensoring to removal of toxic substances both in water and gas treatment. Concluding, it is worth noting that, some chemical-physical features of the 
proposed PBM membranes, such as those related to photometric proprieties, may be exploited in different fields such as sensing.

\section{Acknowledgments}

This work was supported by the European Union within the BioNexGen project (Grant agreement no. CP-FP-246039-2) EUFP7/project.

\section{References}

[1] J. Harlin, Water supply in shared waters, in: J. Forare (Ed.) Drinking Water Sources, Sanitation and Safeguarding, Formas publisher, 2009, pp. 9-19.

[2] L.M. Gan, T.D. Li, C.H. Chew, W.K. Teo, Microporous polymeric materials from polymerization of zwitterionic microemulsions, Langmuir 11 (1995) 3316-3320.

[3] L.M. Gan, C.H. Chew, Microporous polymer composites from microemulsion polymerization, Colloids Surf. A 123-124 (1997) 681-693.

[4] A. Figoli, Synthesis of nanostructured mixed matrix membrane for facilitated gas separation (Ph.D. thesis), University of Twente, The Netherlands, 2001.

[5] W. Meier, Nanostructered synthesis using surfactants and copolymers, Curr. Opin. Colloid Interface Sci. 4 (1999) 6-14.

[6] T.D. Li, L.M. Gan, C.H. Chew, W.K. Teo, L.H. Gan, Hollow-fiber membranes coated with polymerizable bicontinuous microemulsions, J. Membr. Sci. 133 (1997) 177-187.

[7] L.M. Gan, T.H. Chieng, C.H. Chew, S.C. Ng, Microporus polymeric materials from microemulsion polymerization, Langmuir 10 (1994) 4022-4026.

[8] L.M. Gan, J. Liu, L.P. Poon, C.H. Chew, Microporous polymeric composites from bicontinuous microemulsion polymerization using a polymerizable nonionic surfactant, Polymer 38 (1997) 5339-5345.

[9] T.H. Chieng, L.M. Gan, W.K. Teo, Porous polymeric membranes by bicontinuous microemulsion polymerization: effect of anionic and cationic surfactants, Polymer 37 (1996) 5917-5925.

[10] J.H. Burban, M. He, E.L. Cussler, Organic Microporous materials made by bicontinuous microemulsion polymerization, AlChE J. 41 (1995) 907-914.

[11] J.H. Burban, M. He, E.L. Cussler, Silica gels made by bicontinuous microemulsion polymerization, AlChE J. 41 (1995) 159-165.

[12] V. Kochkodan, D.J. Johnson, N. Hilal, Polymeric membranes: surface modification for minimizing (bio)colloidal fouling, Adv. Colloid Interface Sci. 206 (2014) 116-140.

[13] D. Rana, T. Matsuura, Surface modifications for antifouling membranes, Chem. Rev. 110 (2010) 2448-2471.

[14] J.S. Vrouwenvelder, S.M. Bakker, L.P. Wessels, J.A.M. van Paassen, The membrane fouling simulator as a new tool for biofouling control of spiral-wound membranes, Desalination 204 (2007) 170-174.

[15] M. Herrera-Robledo, D.M. Cid-León, J.M. Morgan-Sagastume, A. Noyola, Biofouling in an anaerobic membrane bioreactor treating municipal sewage, Sep. Purif. Technol. 81 (2011) 49-55.

[16] A.S. Gorzalski, O. Coronell, Fouling of nanofiltration membranes in full- and bench-scale systems treating groundwater containing silica, J. Membr. Sci. 468 (2014) 349-359.
[17] P. Kornel, S. Krause, Membrane bioreactors for wastewater treatment, in: N. N. Li, A.G. Fane, W.S.W. Ho, T. Matsuura (Eds.), Advanced Membrane Technology and Applications, Wiley, Hoboken, New Jersey, 2008, pp. 217-237.

[18] L. Shao, Z.X. Wang, Y.L. Zhang, Z.X. Jiang, Y.Y. Liu, S. Key, A facile strategy to enhance PVDF ultrafiltration membrane performance via self-polymerized polydopamine followed by hydrolysis of ammonium fluotitanate, J. Membr. Sci. 461 (2014) 10-21.

[19] X.Q. Cheng, L. Shao, C.H. Lau, High flux polyethylene glycol based nanofiltration membranes for water environmental remediation, J. Membr. Sci. 476 (2015) 95-104.

[20] T.D. Li, L.M. Gan, C.H. Chew, W.K. Teo, L.H. Gan, Preparation of ultrafiltration membranes by direct microemulsion polymerization using polymerizable surfactants, Langmuir 12 (1996) 5863-5868.

[21] A. Figoli, J. Hoinkis, B. Gabriele, G. De Luca, F. Galiano, S.A. Deowan, Bicontinuous Microemulsion Polymerized Coating for Water Treatment, Patent Application PCT/EP2014/070603=WO2014/EP070603, 2014.

[22] X. Zhang, M. Wang, T. Wu, S. Jiang, Z. Wang, In situ gamma-ray initiated polymerization to stabilize surface micelles, J. Am. Chem. Soc. 126 (2004) 6572-6573.

[23] D.J. Johnson, S.A. Al-Malek, B.A.M. Al-Rashdi, N. Hilal, Atomic force microscopy of nanofiltration membranes: effect of imaging mode and environment, J. Membr. Sci. 389 (2012) 486-498.

[24] J. Liu, W.K. Teo, C.H. Chew, L.M. Gan, Nanofiltration membranes prepared by direct microemulsion copolymerization using poly (ethylene oxide) macromonomer as a polymerizable surfactant, J. Appl. Polym. Sci. 77 (2000) 2785-2794.

[25] G. Roshan Deen, L.H. Gan, Y.Y. Gan, A new cationic surfactant N,N0-dimethyl$\mathrm{N}$-acryloyloxyundecyl piperazinium bromide and its $\mathrm{pH}$-sensitive gels by microemulsion polymerisation, Polymer 45 (2004) 5483-5490.

[26] X.J. Loh, G. Roshan Deen, Y.Y. Gan, L.H. Gan, Water-sorption and metal-uptake behavior of pH-responsive poly (N-acryloyl-N'-methylpiperazine) gels, J. Appl. Polym. Sci. 80 (2001) 268-273.

27] L.H. Gan, N.K. Goh, B. Chen, G. Roshan Deen, C.K. Chu, C.H. Chew, Copolymers of N-acryloyl-N'-methylpiperazine and methyl methacrylate: synthesis and its application for $\mathrm{Hg}(\mathrm{II})$ detection by anodic stripping voltammetry, Eur. Polym. J 33 (1997) 615-620.

28] G. De Luca, F. Bisignano, A. Figoli, F. Galiano, E. Furia, R. Mancuso, O. Saoncella, M. Carraro, M. Bonchio, B. Gabriele, Bromide ion exchange with a keggin polyoxometalate functionalized polymeric membranes: a theoretical and experimental study, J. Phys. Chem. B 118 (2014) 2396-2404.

29] A.J. Bromley, R.G. Holdich, I.W. Cumming, Particulate fouling of surface microfilters with slotted and circular pore geometry, J. Membr. Sci. 196 (2002) 27-37.

[30] H.C. Kim, T.P. Russell, Contact of elastic solids with rough surfaces, J. Polym. Sci. Part A: Polym. Chem. 39 (2001) 1848-1854.

[31] M. Elimelech, X.H. Zhu, A.E. Childress, S.K. Hong, Role of membrane surface morphology in colloidal fouling of cellulose acetate and composite aromatic polyamide reverse osmosis membranes, J. Membr. Sci. 127 (1997) 101-109.

[32] E.M. Vrijenhoek, S. Hong, M. Elimelech, Influence of membrane surface properties on initial rate of colloidal fouling of reverse osmosis and nanofiltration membranes, J. Membr. Sci. 188 (2001) 115-128.

[33] R.N. Wenzel, Surface roughness and contact angle, J. Phys. Chem. 53 (1949) 1466-1467.

[34] F. Gregàň, J. Oremusovà, M. Remko, J. Gregàň, D. Mlynarćik, Stereoisomeric Effect on Antimicrobial Activity of a Series of Quaternary Ammonium Salts, I Farmaco (1998) 41-48. 